\title{
Pinart e Balonchard, Fundidores de Tipo no Rio de Janeiro Oitocentista
}

\author{
Pinart and Balonchard, Type Founders in Rio de Janeiro during the 19th century
}

Edna Lucia Cunha Lima

historia do design, design gráfico, fundidoras de tipo

Este artigo trata dos primeiros fundidores de tipo comerciais no Rio de Janeiro no século XIX, Pierre Joseph Pinart e Isaac Balonchard. A pesquisa foi realizada consultando-se a Biblioteca Nacional do Rio de Janeiro ( jornais e almanaques anuais), e o Arquivo Nacional (registros de entradas de estrangeiros no país).

history of design; graphic design; type foundry

This paper on type foundries in Rio de Janeiro during the 19th century, Pierre Joseph Pinart and Isaac Balonchard,. This research was undertaken by consulting the Brazilian National Library (newspapers and almanacks) and the Brazilian National archives (registers of entries of foreigners).

\section{Introdução}

De 1808 até 1821, todo impresso da Corte, ou seja, do Rio de Janeiro, saia das oficinas da Imprensa Nacional. A partir desta data, termina a "prévia censura dos escritos", começa-se verdadeiramente a imprimir comercialmente. Para tanto eram necessários prensas, tinta, papel e tipos móveis.

Sabemos que a Imprensa Nacional teve um setor de fundição a partir de 1810, sem conseguir resolver inteiramente a necessidade de caracteres de imprensa apenas com os tipos que fabricava (fig. 1). No fim da década de 1820 que começam a aparecer no Rio de Janeiro empresas de fabricação manufatureira de tipos e ornamentos tipográficos. Tanto a própria gráfica oficial e quanto as particulares costumavam comprar tipos prontos no exterior.

Figura 1: Fundidora de tipos no século XVIII, provável modelo para similares cariocas.

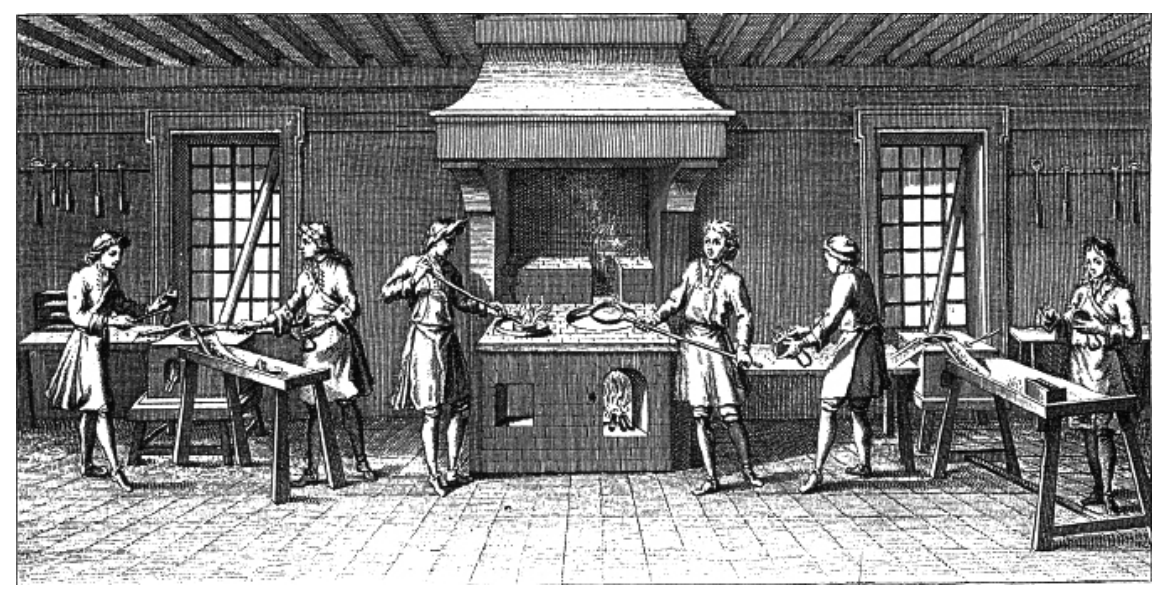

As primeiras fundições de tipo comerciais a se instalar no Rio são possivelmente as pioneiras no país, dado esse que futuras pesquisas poderão ou não confirmar. 


\section{A chegada dos primeiros fundidores franceses}

Não é atribuída a vinda de franceses para o Brasil a um movimento migratório organizado em nenhuma das duas pontas, França ou Brasil. Deve-se antes ao interesse de indivíduos para imigrar para um país que cronistas do princípio do século XIX viam como paradisíaco, nisso contando com a influência de escritores e intelectuais de seu próprio país como Ferdinand Denis que escrevem elogiando o Brasil. Se de um lado o espírito romântico atraia pessoas para uma aventura além-mar, razões práticas davam sustentação a essas aventuras. Pelo menos no ramo gráfico, encomendas constantes de prelos, tipos, vinhetas, papéis e tintas nas empresas parisienses indicavam que os setores editoriais e jornalísticos estavam em crescimento, o que não escapava a jovens empreendedores franceses.

Desde 1821, quando o Governo permitiu o estabelecimento de gráficas particulares para impressão de jornais, livros e revistas, que a demanda de materiais para oficinas tipográficas vinha aumentando. É verdade que esta permissão não significava liberdade de imprensa, estabelecendo-se uma censura sobre os textos já impressos. Há poucos estudos sobre material impresso para fins comerciais essenciais para a administração e divulgação de produtos e empresas comerciais e industriais no Brasil.

Enquanto o cenário para a independência brasileira se delineava, a tipografia francesa gozava ainda de grande prestígio. Desde o século XVII que os tipos baseados nos de Claude Garamond eram a base da composição para textos corridos e graças a Fournier e aos Didot foi realizada a adoção de uma unidade tipográfica, o ponto Didot, que representou um grande avanço na industrialização dos caracteres. No alvorecer do século XIX, começa a padronização na indústria gráfica de grande importância, quando os tipos passam a ter a altura padrão 62,5 pontos, permitindo que se misturassem caracteres de origens diferentes. Os corpos, ou seja, os tamanhos, passam a ser sistematicamente medidos em pontos: 8 , $10,12,14$, etc. até 90 pontos, facilitando o compra e a venda de materiais para composição. $\mathrm{Na}$ Inglaterra, fundidores voltados para as novas necessidades da indústria emergente destacam-se dos modelos livrescos do passado para criar tipos vitorianos cada vez mais ornamentais e chamativos, especiais para serem vistos à distância, aplicados em cartazes e anúncios impressos. É nesse momento de reorganização da indústria gráfica no setor de fundição que finalmente começam a se estabelecer empresas gráficas no Rio de Janeiro e, aos poucos, as fundidoras de tipo para alimentar os setores de composição.

\section{Pierre Joseph Pinart}

O primeiro de todos os fundidores a se estabelecer no Rio de Janeiro parece ter sido Pierre Joseph Pinart. A evidência é que viera para o Rio de Janeiro em fins da década de 1820, tanto que anuncia no Diário do Rio de Janeiro em 3 de fevereiro de 1829 a abertura de sua "fundição de caracteres de imprensa" situada na Rua dos Ourives n ${ }^{\circ} 43$. Mas logo desiste do negócio e publica outro anúncio neste mesmo jornal em 25 de janeiro de 1832 promovendo a venda de "um sortimento de moldes para uma fundição de tipos". O que chama de moldes é provavelmente um conjunto de matrizes para fundição, mais do que os próprios moldes manuais para inserção de matrizes. Esta nomenclatura confusa pode ser encontrada em outros documentos consultados da mesma fase no Brasil.

Depois disso Pierre Joseph Pinart desaparece para ressurgir brevemente no Almanaque Plancher de 1832, como armeiro. Foi uma experiência rápida, de cerca de dois anos como fundidor e não muito bem sucedida, mas pioneira.

\section{Isaac Balonchard}

$\mathrm{Em} 1^{\circ}$ de julho de 1837 aporta no Rio de Janeiro o brigue francês $L$ 'Ursin, vindo do Havre. Entre seus passageiros está um casal com dois filhos, um menino e uma menina. São franceses que vieram tentar a vida do outro lado do mundo. A mulher, que não deixou o nome próprio registrado na Polícia ao entrar, tem 30 anos e abrirá, no ano seguinte, um pequeno negócio de venda de "flores, fitas finas e outros objetos de enfeite" (Jornal do Commercio, 26 de janeiro de 1838). É dessa forma que contribuirá para o orçamento 


\section{Infodesıgn}

doméstico, enquanto o marido estabelece a primeira fundidora de tipos comercial duradoura do Rio de Janeiro.

Isaac Balonchard tinha 36 anos quando desembarcou e declarou que era retratista ou estampador. No fim do mesmo mês, anunciava a que veio (Jornal do Commercio, 31 de julho de 1837):

Balonchard, chegado a pouco de Paris, tem a honra de prevenir os srs. Impressores desta capital que ele tem estabelecido, na Rua da Guarda Velha no 32, uma fundição de tipos. Ele espera, pela moderação de seus preços e pela perfeição de suas obras, obter a confiança dos seus fregueses. No mesmo estabelecimento, vende-se tinta de imprimir.

Uma empresa fundidora de tipos nos anos 1800 podia contar com matrizes prontas, compradas nas grandes casas européias na França, Inglaterra, Holanda e Estados Unidos. Havia de fato um comércio de matrizes que corria ao lado daquele da venda dos próprios tipos. Eram vendidas matrizes acabadas e por acabar, estas últimas mais em conta, o que exigia que um especialista as retificasse. É de se supor que mesmo sem que fossem gravadores de punções completos, pessoas como Balonchard deviam estar plenamente habilitados para fazer estas operações e também reparos nas matrizes prejudicadas pelo desgaste devido ao uso.

No Brasil, havia gravadores de punção trabalhando em outros ramos, em especial na Casa da Moeda e como ourives para as joalherias da cidade. O trabalho sistemático e criativo de gravar uma fonte inteira, caixa alta e baixa e ainda os acentos, numerais, sinais matemáticos e gramaticais, não parece ter sido praticado nas fundidoras de tipo cariocas do século XIX.

Entre 1821, quando foi permitida, pelo decreto de 9 de março, a instalação de gráficas no país sob a vigilância da censura, até a chegada de Balonchard em 1837, portanto por dezesseis anos, o número de gráficas particulares havia crescido continuamente. $\mathrm{O}$ Almanach do Rio de Janeiro de 1824, editado pela Imprensa Nacional, assinalava a existência de cinco gráficas comerciais no Rio de Janeiro: a Tipografia de Silva Porto \& Cia. na Rua do Espírito Santo, a Tipografia do Diário na Rua dos Barbonos, a Tipografia de Torres na Rua do Piolho e a Tipografia de Plancher na Rua dos Ourives.

Figura 2: Anúncio da Fundidora Francesa no Almanack Laemmert de 1869, empresa sucessora de Isaac Balonchard.

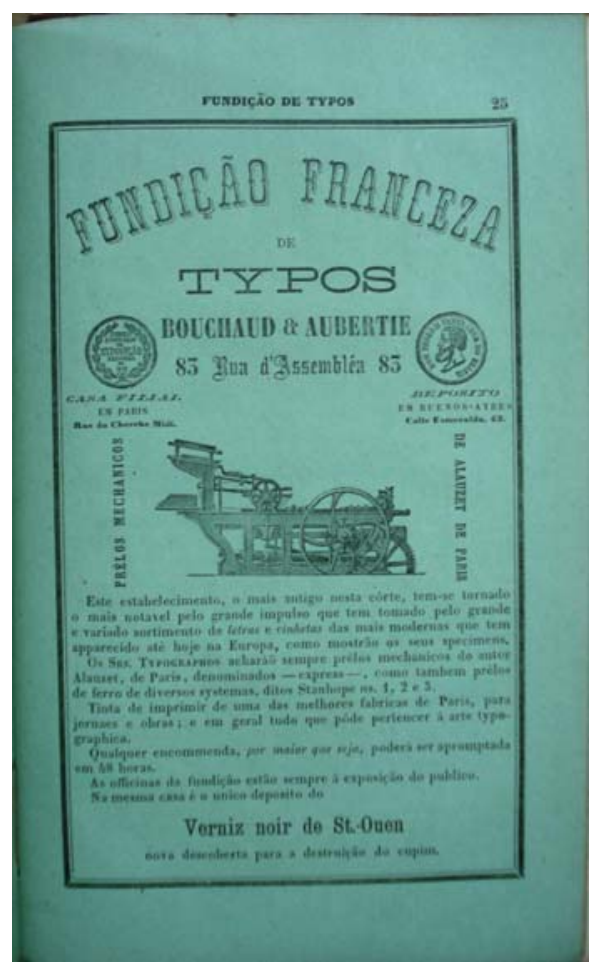


Já Moreyra de Azevedo (1862), que escreve sobre a imprensa carioca ainda no Segundo Reinado, contabiliza em 1832, mais três, e dez anos mais tarde, o total perfaz doze tipografias. Os principais jornais da fase já se estabeleceram: o Diário do Rio de Janeiro (1821) e o Jornal do Comércio (1827), esse último por Pierre Plancher. É nos anúncios destes jornais, antes da aparição do anuário Almanack Laemmert, em 1844, que pode ser acompanhado o panorama de chegadas e estabelecimentos de técnicos gráficos no Rio de Janeiro.

Pesquisando nos Almanacks Laemmert de 1844 até 1900, mantendo, portanto, o foco no século XIX, não foram detectados gravadores de punções nos anúncios das empresas que operavam no mercado carioca. Estes anúncios dão indícios de que tipos e matrizes eram comprados no exterior, e que eram usadas máquinas fundidoras nas empresas que aqui operavam, e que estas vendiam e anunciavam máquinas e utensílios para oficinas tipográficas e litográficas (figura 2). Não foi encontrado um só anúncio de venda de maquinário e de utensílios para fundição de tipos além do publicado por Pinart no Jornal do Commercio em 1832. Mas sem dúvida que as empresas, dirigidas por franceses, na maior parte, mas também por brasileiros e portugueses, fabricavam localmente tipos e usavam equipamentos importados, por vezes citados nos anúncios.

Era comum que importadoras de material gráfico vendessem sejam insumos como papel e tinta ou maquinário, como prensas, e ainda anunciassem a venda de tipos das principais fundidoras européias, citando-as. As compras de matrizes para renovação do estoque são anunciadas, mas não são vendidas ao público em geral.

Tanto que Isaac Balonchard, o primeiro fundidor presente nas páginas do Almanack Laemmert de 1844, assim se apresentava no Jornal do Comercio de 3 de janeiro de 1844:

Fundição de tipos de Balonchard

Rua da Cadeia, no 93, no Rio de Janeiro.

O anunciante se encarrega de encomendas, tanto para esta cidade como para o interior, e para fora do Império. Os tipos em que são impressos o Jornal do Comércio e o Diário do Rio são desta fundição, onde aliás se acha um muito variado sortimento de outros tipos, vinhetas, fillets, entrelinhas, caxinhas, números e letras para marcar roupa, etc., tudo do mais moderno e do melhor gosto

Esse anúncio foi repetidamente impresso durante este mesmo ano. O que se pode concluir é que ele fundia, além das letras, ornamentos como fios e vinhetas e ainda entrelinhas. Para entender estes anúncios é preciso ter em mente que uma página composta com tipos móveis de metal comportava tanto o que vemos e fica em relevo quanto os espaços em branco rebaixados. A parte que vemos impressa é em relevo, como tipos, ornamentos, fios, pequenas ilustrações. A forma para impressão era preenchida com peças rebaixadas de metal (guarnições) que correspondiam aos espaços em branco, o que inclui as entrelinhas e as entreletras. Neste anúncio encontramos artigos provavelmente correspondentes a carimbos para marcar tecido com letras e números, auxiliando a identificação dos donos das roupas, essencial em famílias extensas e nas escolas internas, tão comuns no Segundo Reinado.

Sem dúvida que a venda de tipos e demais materiais para composição para jornais importantes, em especial o Jornal do Comércio, foi um negócio que garantiu ao fundidor um lugar na praça carioca, mas a ausência de concorrentes era evidente. Balonchard pode ter vindo ao Brasil atraído por encomendas destes periódicos. É mesmo possível que Plancher o tenha atraído para o país, tendo em vista a necessidade de renovar seus tipos. Mas o mais provável é que ainda na França, tenha reconhecido a existência de uma demanda a partir da freqüência com que os impressores brasileiros faziam encomendas de tipos no exterior. Como ainda não foi apurado onde vivia e trabalhava antes de chegar aos portos cariocas, podemos apenas supor.

O fundidor francês havia inicialmente aberto sua oficina na Rua da Guarda Velha que é a atual Rua 13 de Maio. No ano seguinte, muda-se para a Rua da Cadeia $n^{\circ} 105$, e deve ter se mudado novamente para o $\mathrm{n}^{\circ} 93$ neste meio tempo, pois esse é o endereço que cita também no seu primeiro anúncio no Almanack Laemmert de 1844, correspondente ao ano de 1843. A Rua da Cadeia é a atual Rua da Assembléia. Estas ruas eram próximas do porto, facilitando importação de materiais, e próximas das redações dos jornais e de suas oficinas tipográficas, principais clientes deste tipo de negócio. 


\section{Infodesıgn}

Isaac Balonchard orgulha-se de sua posição de pioneiro, tanto que se intitula "primeiro fundidor europeu vindo em socorro da imprensa brasileira" (Jornal do Comercio, 15 de outubro de 1848). Será que Pinart chegou efetivamente a produzir tipos na sua breve incursão na área? E ele se firma entre os fornecedores das gráficas cariocas, anunciando sua oficina continuamente desde 1837 até 1847, por dez anos, portanto. Tornará a aparecer no Almanack Laemmert por mais três vezes, deixando de constar na lista em 1848. Nos quatro anuários em que comparece, apresenta-se da mesma maneira:

Balonchard, Fundidor de Tipos, Rua da Cadeia, 93.

O anuário em que os anúncios foram publicados é o famoso Almanack Laemmert. Trata-se de uma lista de comerciantes, industriais, servidores públicos e profissionais liberais, empresas, associações, clubes e teatros, enfim das pessoas e firmas atuantes no Rio de Janeiro, então sede da Corte e capital do país, seguida do endereço e, em alguns casos de detalhes da empresa ou particular, além de outras informações sobre calendário, composição da Família Real, legislação e taxas, etc. Depois começa a incluir notícias de outras cidades do Rio de Janeiro, como Niterói, Campos, etc. A edição de um ano é sempre relativa ao ano anterior. Foram editados pelos irmãos Henrique e Eduardo Laemmert, conceituados livreiros, proprietários da Livraria Universal da Rua do Ouvidor. Eles começam a editar livros em 1837, uma Folhinha Popular e finalmente o Almanack, a partir de 1844. Estas publicações eram impressas na Tipografia Universal, da mesma empresa, com a variedade de fontes típica desta fase. As listas de profissionais era separada em grandes grupos, sendo um deles o dos Fundidores e Maquinistas. Balonchard é o único fundidor de tipos a anunciar nessa categoria que reunia desde fabricantes de máquinas (os maquinistas) aos que faziam grades de metal fundido. Em 1847, os Maquinistas se separam dos Fundidores e seu nome, sempre o único, aparece nesse ultimo setor.

Não tendo publicado um catálogo de seus tipos, ou se o fez que este objeto tivesse chegado até nossos dias, cabe-nos observar os periódicos que aponta como clientes da oficina para ter uma idéia bastante imprecisa de sua produção. Não se sabe igualmente o tamanho de sua empresa, se empregava escravos, por exemplo, ou quantos e quais os seus empregados. Serão eles que, possivelmente, irão assumir oficinas de fundição de tipos posteriormente. Balonchard não deixou registros na Junta Comercial, fundada anos mais tarde.

Em 18 de junho de 1847, outro anúncio no Jornal do Comércio estabelece o ano de seu falecimento e que era católico:

"Os amigos do Sr. Balonchard são rogados de assistirem ao seu enterro que terá lugar hoje, às quatro horas da tarde, na Igreja de Santo Antonio."

Curiosamente, seus sucessores no negócio de fundição de tipos, Pedro Secretan e Eugênio Bouchaud, chamam-no de João Balonchard. João ou Isaac teria morrido com 46 anos, os dez últimos dos quais vividos no Rio de Janeiro, deixando sua contribuição como pioneiro franco- brasileiro na fundição de tipos.

O sobrenome Balonchard desaparece dos registros do Almanack, mas na Rua da Assembléia e em suas redondezas veremos que diversos fundidores de tipo irão se estabelecer no decorrer do século XIX em terras cariocas.

\section{Conclusão}

Embora Pinart seja cronologicamente o primeiro fundidor de tipos carioca, é seu contemporâneo Balonchard quem efetivamente dá inicio a fundição comercial de tipos no Rio de Janeiro. Seu acervo vai sendo comprado e ampliado por seus conterrâneos, sendo a base para o estabelecimento da Fundidora de Tipos Francesa que, contando sua fundação a partir de Balonchard, perfaz mais de sessenta anos de existência, sobrevivendo até as portas do século XX.

Quando estudamos a fundição de tipos nem sempre encontramos os criadores de novos alfabetos, mas sim modestos artesãos que sabem como reproduzir matrizes fazendo os tipos de metal. O que foi escrito nesse artigo diz respeito a essas pessoas, cujas vidas decorreram na obscuridade que marca o artesão e o operário na nossa realidade. Ao invés 
de belos catálogos com os materiais produzidos no Brasil, contamos, na maior parte, com anúncios nos jornais brasileiros onde as empresas costumam vender seus produtos.

\section{Agradecimento}

A autora agradece a Fundação Biblioteca Nacional do Rio de Janeiro pelo apoio à sua pesquisa.

\section{Referências}

ALMANAQUE DO RIO DE JANEIRO. Rio de Janeiro: Imprensa Nacional (1821-1832)

ALMANAQUE Plancher. Rio de Janeiro: Tipografia de Plancher, 1832.

ALMANAK LAEMMERT - Almanak Administrativo, Mercantil e Industrial do Rio de Janeiro (1890-1900) - Coleção de microfilmes da Biblioteca Nacional do Rio de Janeiro.

ALMANAK LAEMMERT - Almanak Administrativo, Mercantil e Industrial do Rio de Janeiro (1844-1889) $-$ site Brazilian Government Document Digitalization Project, 2008. http://www.crl.edu/content/almanak2.htm ,31/04/2009.

ARQUIVO NACIONAL, Livro de Registros- Polícia. Entrada de embarcações e passageiros. Cod. 414, v.3, f.366, $1^{\circ}$ de julho de 1837, sobre Balonchard

ARQUIVO NACIONAL - Polícia. Legitimações. Passaportes. Cod. 381, v. 9, f.38, 9 de julho de 1837, sobre Balonchard

Azevedo, Moreyra de. Origem e Desenvolvimento da Imprensa no Rio de Janeiro. Revista do Instituto Histórico e Geográfico. Tomo 28, Parte II, $4^{\circ}$ trimestre de 1865, p. 169-224

DIÁRIO DO RIO DE JANEIRO (1821-1850). Coleção de microfilmes da Biblioteca Nacional do Rio de Janeiro.

DIDEROT e D'ALEMBERT. Encyclopédie, ou Dictionnaire raisonné des sciences, des arts et des métiers. Paris, 1751.

FERREIRA, O.C. Notas datilografadas não publicadas, S/d

GODINHO, Margarida C. Gráfica, arte e indústria no Brasil: 180 anos de história. São Paulo: Bandeirantes, 1991

HALLEWELL, Lawrence. O Livro no Brasil: sua história. São Paulo: EDUSP, 2005.

JORNAL DO COMMERCIO (1827-1850). Coleção de microfilmes da Biblioteca Nacional do Rio de Janeiro.

MULLEN, Robert A. Recasting a craft. St. Louis Typefounders respond to industrialization.Carbondale: Southern Illinois University Press, 2005.

UPDIKE, Daniel. Printing Types. Cambridge: University Press, 1937.

VERLOMME, Malou. Technological Shifts in Type Design and Production. Dissertação de Mestrado (MFA) em Typeface Design Universidade de Reading, 2005.

\section{Sobre a autora}

Edna Lucia Cunha Lima é doutora em Comunicação pela Universidade Federal do Rio de Janeiro (2003). Atualmente é professor adjunto da Pontifícia Universidade Católica do Rio de Janeiro.

<ednacunhalima@gmail.com> 